\title{
Avaliação do Comportamento Agronômico da Planta e Valor Nutritivo da Silagem de Diferentes Híbridos de Milho (Zea mays, L.) ${ }^{1}$
}

\section{Joilmaro Rodrigo Pereira Rosa ${ }^{2}$, José Henrique Souza da Silva ${ }^{3}$, João Restle ${ }^{4}$, Leonir Luiz Pascoal $^{5}$, Ivan Luiz Brondani 6 , Dari Celestino Alves Filho ${ }^{7}$, Aline Kellermann de Freitas ${ }^{8}$}

\begin{abstract}
RESUMO - O experimento foi desenvolvido com o objetivo de avaliar o comportamento agronômico produtivo da planta e as características químico-bromatológicas e fermentativas da silagem de diferentes híbridos de milho (Zea mays, L.): Agroceres AG-5011, Braskalb XL-344 e Cargill C-806. Para as avaliações agronômicas dos híbridos, utilizou-se o delineamento experimental inteiramente casualizado e, para a avaliação das silagens, o delineamento de blocos ao acaso, sendo o critério de bloqueamento o período de utilização da silagem. O híbrido C-806 foi o mais precoce, com intervalo de 100 dias da semeadura à colheita para ensilagem, enquanto o híbrido XL-344 foi o mais tardio, com intervalo de 121 dias. As características fenotípicas da planta de milho determinaram o potencial produtivo dos híbridos, tendo o híbrido AG-5011 apresentado a maior altura de planta e potencial produtivo de matéria verde e matéria seca por hectare, em relação aos híbridos C-806 e XL-344. Verificou-se, nos híbridos AG-5011 e C-806, maior população final de plantas em relação ao híbrido XL-344. O híbrido C-806 apresentou menor proporção de grãos em relação à planta inteira. Com base nos teores de MS e DIVMS, as silagens dos híbridos AG-5011, C-806 e XL-344 são classificadas como de boa qualidade. Com relação às características fermentativas, $\mathrm{N}-\mathrm{NH}_{3} / \mathrm{NT}$ e $\mathrm{pH}$, as silagens dos três híbridos são classificadas como de muito boa qualidade.
\end{abstract}

Palavras-chave: colmo, folhas, grão, nitrogênio amoniacal, pH, produção de matéria seca

\section{Evaluation of the Agronomic Behavior of the Plant and Nutritive Value of Silage from Different Corn (Zea mays, L.) Hybrids}

\begin{abstract}
The experiment was conducted with the objective to evaluate the agronomic production behavior of the plant and the chemical, qualitative and fermentation characteristics of silage from different corn (Zea mays, L.) hybrids: Agroceres AG-5011, Braskalb XL-344 and Cargill C-806. For the agronomic behavior of the hybrids a complete randomized experimental design was used, and for silages evaluation a randomized block design was used, where the silage utilization period was the blocking criterion. C-806 hybrid was the most precocious with an interval of 100 days between sowing and harvesting, while the XL-344 was the latest with 121 days. The plant phenotypic characteristics determined the production potential of the hybrid. AG-5011 showed taller plants and higher production potential of fresh and dry matter per ha, in relation to the XL-344 and C-806 hybrids. The final number of plants/ha was higher for the AG-5011 and C-806 hybrids. The C-806 hybrid showed the lowest grain proportion in relation to the whole plant. Based on the dry matter and in vitro dry matter digestibility, the silages of the three hybrids are classified as of good quality. Based on the fermentation, characteristics $\mathrm{N}-\mathrm{NH}_{3} / \mathrm{NT}$ and $\mathrm{pH}$, the silages of the hybrids are classified as of very good quality.
\end{abstract}

Key Words: ammonia nitrogen, grain, leaves, $\mathrm{pH}$, production of dry matter, stem

\section{Introdução}

A grande necessidade de atender à produção intensiva de bovinos e a estacionalidade produtiva de forragens de boa qualidade impulsionam produtores a adotarem práticas de conservação de forragens, difundindo cada vez mais o processo de ensilagem.
A adoção da silagem como volumoso tornou-se uma técnica muito desenvolvida entre terminadores de bovinos de corte em confinamento. Pimentel et al. (1998) relatam que, para produção de silagem, há necessidade de uma espécie forrageira que apresente produção elevada de massa por unidade de área e que seja um alimento de alta qualidade para os animais. McDonald et

\footnotetext{
1 Parte da Dissertação apresentada à UFSM para obtenção do título de Mestre do primeiro autor.

2 Engo-.-Agro., MSc., Aluno do Programa de Pós-Graduação da UFRGS, Porto Alegre, RS. E.mail: joilmaro.rosa @ terra.com.br

3 Engo-Agro., PhD, Professor Titular do Departamento de Zootecnia da UFSM, Santa Maria, RS. E.mail: jhen@ @cr.ufsm.br

${ }^{4}$ Engo-.Agro., Pesquisador do CNPq. Professor Visitante da UFG, Goiânia - GO. E.mail: jorestle @ terra.com.br

5 Zootecnista, MSc., Professor do Departamento de Zootecnia da UFSM, Santa Maria, RS. E.mail: pascoall @ terra.com.br

6 Zootecnista, Dr., Professor do Departamento de Zootecnia da UFSM, Santa Maria, RS. E.mail: brondani@ccr.ufsm.br

7 Engo.-Agro., MSc., Professor do Departamento de Zootecnia da UFSM, Santa Maria, RS. E.mail: dcafilho@terra.com.br

8 Zootecnista, Aluna do Programa de Pós-Graduação da UFG, Goiânia, GO.
} 
al. (1991) consideram a planta de milho ideal para ensilagem, já que contém quantidade relativamente alta de matéria seca, pequena capacidade tampão e níveis adequados de carboidratos solúveis para fermentação.

A falta de informações regionais, pertinentes ao comportamento agronômico produtivo e valor nutritivo dos diversos materiais genéticos existentes no mercado, tornou-se um obstáculo para o melhor planejamento da escolha dos híbridos de milho que se destinem à produção de silagem. Portanto, a caracterização agronômica dos materiais genéticos disponíveis no mercado é de fundamental importância para se obter alta produção de silagem com elevado valor nutritivo. Segundo Almeida Filho et al. (1999), a identificação de plantas mais adaptadas às condições em que serão cultivadas contribuirá para maiores rendimentos da cultura do milho, ressaltando que, além da genética, a produção é influenciada, entre outros fatores, pela qualidade das sementes, época de semeadura, população de plantas, preparo, correção e adubação do solo, controle de plantas daninhas, pragas e doenças, irrigação, entre outros. Contudo, existem poucas informações sobre os efeitos destes fatores sobre a qualidade da forragem produzida.

Segundo Van Soest (1994), a qualidade da silagem também pode ser influenciada, entre outros fatores, pelo processo fermentativo da massa, uma vez que, durante a ensilagem, pode ocorrer redução do valor nutritivo pela respiração, fermentação aeróbia, processos de decomposição ou perdas de efluentes. Entre os parâmetros que determinam boa fermentação, estão como bons indicadores o monitoramento dos valores de $\mathrm{pH}$ e concentração de nitrogênio amoniacal (N-NH $/$ /NT).

A otimização de sistemas intensivos de produção pecuária depende da produção de silagem de baixo custo e de alto valor nutritivo, para que o giro de capital investido seja feito no menor tempo possível (Brondani et al., 2000). Assim, de modo geral, pesquisas de comparação entre híbridos são fundamentais para o avanço dos programas de melhoramento genético e importantes na recomendação a técnicos e produtores sobre o híbrido destinado à produção de silagem com melhor relação produção:valor nutritivo.

Os híbridos de milho Agroceres AG-5011, Braskalb XL-344 e Cargill C-806 encontram-se disponíveis no mercado, sendo considerados materiais de primeira linha das empresas de melhoramento, destinados a suprir as necessidades dos produtores em relação a materiais com melhores características para produção de silagem de alto valor nutritivo.
Este trabalho foi conduzido com o objetivo de avaliar o comportamento agronômico da planta e as características químico-bromatológicas e fermentativas das silagens de diferentes híbridos de milho.

\section{Material e Métodos}

O experimento foi desenvolvido no Setor de Bovinocultura de Corte do Departamento de Zootecnia da Universidade Federal de Santa Maria, localizada fisiograficamente na Depressão Central do Estado do Rio Grande do Sul, a uma altitude de $95 \mathrm{~m}$. Conforme a classificação de Köppen, o clima da região é o Cfa (subtropical úmido), com precipitação média anual de $1.769 \mathrm{~mm}$, temperatura média anual de $19,2^{\circ} \mathrm{C}$, média mínima de $9,3^{\circ} \mathrm{C}$ em julho e média máxima de $24,7^{\circ} \mathrm{C}$ em janeiro, insolação de 2.212 horas anuais com umidade relativa do ar de 82\% (Moreno, 1961).

A classificação do solo da área experimental é apresentada como podzólico vermelho-amarelo pertencente à unidade de mapeamento São Pedro, que se caracteriza por apresentar solos de textura superficial arenosa e friável, sendo naturalmente ácidos, pobres em matéria orgânica e, na maioria dos nutrientes, com baixa saturação de bases (DNPEA-Brasil, 1973).

O trabalho de pesquisa compreendeu o período de 12 de dezembro de 1999 a 12 de novembro de 2000. As silagens dos materiais avaliados, Agroceres AG-5011, Braskalb XL-344 e Cargill C-806, foram produzidas em uma área total de 12 ha, que vem sendo utilizada ao longo dos anos com pastagens cultivadas de gramíneas de estação fria e lavouras de milho destinadas à produção de silagem durante a estação quente, em experimentos com produção animal, recebendo, durante cada período de cultivo adubações de fósforo, potássio e nitrogênio, conforme a EMBRAPA (1995).

As lavouras de cada híbrido de milho foram avaliadas em uma área de quatro ha com características de manejo e fertilidade de solo adequadas ao cultivo do milho. Os híbridos foram semeados nos dias 14 e 15 de dezembro de 1999 em sistema de plantio direto na resteva da mistura forrageira aveia (Avena strigosa, S.) e azevém (Lolium multiflorum, L.), dessecada com glifosato + óleo mineral. A plantadeira utilizada foi regulada com espaçamento entre linhas de $0,9 \mathrm{~m}$, profundidade de semeadura de $3,5 \mathrm{~cm} \mathrm{e}$ distribuição de 5,5 sementes por metro linear. As sementes dos híbridos de milho foram tratadas com inseticida à base de tiodicarb (promet) anteriormente ao plantio.

\section{R. Bras. Zootec., v.33, n.2, p.302-312, 2004}


A adubação de base foi constituída de $450 \mathrm{~kg} / \mathrm{ha}$ de adubo NPK na formulação 10-18-20 na metade da área destinada a cada híbrido (2 ha) e na outra metade, de $450 \mathrm{~kg} / \mathrm{ha}$ de adubo organo-mineral na formulação 08-10-08, conforme a EMBRAPA-CNPT (1995), e em cobertura, realizada 30 dias após o plantio, $150 \mathrm{~kg} / \mathrm{ha}$ de uréia. Durante a condução da lavoura, efetuou-se o controle químico de plantas daninhas, com a utilização dos produtos atrazine + simazine (primatop) e nicosulfuron (sanson), em dosagem recomendada pelo fabricante.

As lavouras foram colhidas quando os grãos de cada híbrido se encontravam entre o final do estádio pastoso e farináceo. O corte das plantas para o processo de ensilagem foi feito com uma ensiladeira regulada com tamanho médio do picado entre 1 e 1,5 cm e altura de corte média de $20 \mathrm{~cm}$. O material colhido foi transportado da área de cultivo e armazenado em local previamente nivelado e bem drenado, sendo compactado com o auxílio de um trator, em silos de superfície tipo "torta", vedados e protegidos com lona plástica de polietileno de três camadas.

As avaliações das lavouras foram realizadas por ocasião do corte dos híbridos para silagem, tomando-se, como parâmetros de avaliação, a população final, o ciclo da lavoura, a altura da planta e altura da inserção da espiga. Por ocasião da colheita dos materiais, efetuou-se também a avaliação produtiva para determinação dos rendimentos de matéria verde total e matéria seca ensilável. Utilizaram-se duas repetições para cada adubo dentro dos híbridos de milho. Aleatoriamente, foram coletadas, em cada repetição, cinco amostras com plantas inteiras. Cada amostra constituiu-se de três metros lineares de linha de plantio. As plantas foram cortadas manualmente a $20 \mathrm{~cm}$ do solo e retiradas juntamente com o colmo remanescente (toco). Posteriormente, as plantas pertinentes a cada amostra foram pesadas e medidas individualmente e, na sequiência, fragmentadas em seus componentes: colmo remanescente (toco), colmo, folhas (verdes e senescentes), espigas (palhas, sabugos e grãos) e pendão, permitindo, assim, a determinação da estrutura física percentual dos componentes da planta dos híbridos avaliados.

A abertura dos silos ocorreu, em média, 97 dias após o seu fechamento, para o fornecimento aos animais confinados. Para avaliação da silagem, foi coletado material a cada 21 dias, correspondente aos períodos de utilização da silagem. As amostras do material foram pesadas e pré-secas em estufa de ar forçado a $60^{\circ} \mathrm{C}$, por 72 horas, retiradas e pesadas novamente para determinação do teor de matéria seca ao ar e, na seqüência, processadas em moinho tipo "Willey", com peneira de um milímetro.

Uma fração de cada amostra de silagem foi congelada na forma in natura e, posteriormente, triturada e utilizada para análise do $\mathrm{pH}$, utilizando-se potenciômetrodigital(Digimed), edonitrogênioamoniacal como porcentagem do nitrogênio total $\left(\mathrm{N}-\mathrm{NH}_{3} / \mathrm{NT}\right)$, conforme técnica descrita pelo AOAC (1995).

Nas amostras de silagens pré-secas, determinou-se o teor de matéria seca total (MS) em estufa a $105^{\circ} \mathrm{C}$, nitrogênio total (NT) pelo método micro Kjeldahl, sendo multiplicado pelo fator 6,25 para obtenção do teor de proteína bruta $(\mathrm{PB})$ e matéria mineral $(\mathrm{MM})$ por incineração a $55^{\circ} \mathrm{C}$. O teor de matéria orgânica (MO) foi obtido por diferença (\% $\mathrm{MO}=100-\mathrm{MM})(\mathrm{AOAC}, 1984)$. A digestibilidade in vitro da matéria orgânica (DIVMO) foi determinada conforme técnica descrita por Tilley \& Terry (1963). O teor de fibra em detergente neutro (FDN) foi determinado conforme Goering \& Van Soest (1970) e os teores de fibra em detergente ácido (FDA), bem como dos constituintes da fração fibrosa: hemicelulose (HEM), celulose (CEL) e lignina (LIG), segundo AOAC (1995). O teor de matéria orgânica digestível na MS foi calculado com base no teor de MO e na DIVMO das silagens avaliadas, em que $\%$ MOD $=$ MO*DIVMO.

Os valores de nutrientes digestíveis totais (NDT) foram obtidos por intermédio da equação de regressão recomendada pela Latin American Tables of Feed Composition (1974), com base nas análises de $\mathrm{PB}, \mathrm{EE}, \mathrm{FB}$ e extrativos não nitrogenados (ENN). Para o cálculo da energia digestível (ED, Mcal/kg de MS), utilizou-se a equação sugerida pelo ARC (1980), com base na digestibilidade in vitro da matéria orgânica (DIVMO, \%) e na matéria orgânica (MO, \%) das silagens, em que ED $=($ DIVMO*MO*19 $) \div 4,184$, sendo calculado ainda, a partir desta, a energia metabolizável (EM), multiplicando a ED pelo fator 0,82 e as energias líquidas de mantença (Elm) e de ganho (Elg), segundo o NRC (1984).

Para avaliação do comportamento agronômico de cada híbrido, utilizou-se o delineamento experimental inteiramente casualizado, com duas repetições com cinco amostras cada, testando três tratamentos (AG-5011, XL-344 e C-806). Como a área de lavouras continha subparcelas com diferentes adubações, este fator foi incluído no modelo estatístico, a fim de

\section{R. Bras. Zootec., v.33, n.2, p.302-312, 2004}


que esta fonte de variação fosse removida do erro, sendo que, para análise e interpretação dos resultados deste trabalho, o efeito do adubo não foi considerado.

Os dados coletados foram submetidos à análise de variância, aplicando-se o teste F e o teste Tukey, em nível de significância de 5\%, seguindo o modelo estatístico abaixo:

$$
\mathrm{Y}_{\mathrm{ijkl}}=\mu+\tau_{\mathrm{i}}+\alpha_{\mathrm{j}}+(\tau \alpha)_{\mathrm{ij}}+\beta_{\mathrm{k}}(\tau \alpha)_{\mathrm{ij}}+\varepsilon_{\mathrm{ijkl}}
$$

em que: $Y_{\mathrm{ijkl}}$ refere-se às variáveis dependentes; $\mu$, à média das observações; $\tau_{i}$, ao efeito do i-ésimo híbrido de milho, sendo 1 (AG-5011), 2 (XL-344) e 3 (C-806); $\alpha_{\mathrm{j}}$, ao efeito do j-ésimo tipo de adubo, representando 1 o adubo orgânico e 2 o adubo quími$\operatorname{co} ;(\tau \alpha)_{\mathrm{ij}}$, à interação entre híbrido e adubo; $\beta_{\mathrm{k}}(\tau \alpha)_{\mathrm{ij}}$, ao erro experimental (repetição dentro de híbrido $\mathrm{x}$ adubação); $\varepsilon_{\mathrm{ijkl}}$, à variação aleatória residual (erro amostral).

Para avaliação das silagens de cada híbrido, utilizou-se o delineamento de blocos ao acaso com quatro repetições, sendo o critério de bloqueamento o período de utilização da silagem de milho:

$$
\mathrm{Y}_{\mathrm{ij}}=\mu+\tau_{\mathrm{i}}+\beta_{\mathrm{j}}+\varepsilon_{\mathrm{i}}
$$

em que: $\mathrm{Y}_{\mathrm{ij}}$ refere-se às variáveis dependentes; $\mu$, à média das observações; $\tau_{\mathrm{i}}$, ao efeito da i-ésima silagem de milho, sendo 1 (AG-5011), 2 (XL-344) e 3 (C-806); $\beta_{\mathrm{j}}$, ao efeito de bloco (período de utilização da silagem) de ordem $\mathrm{j}$, sendo 1 (primeiro período), 2 (segundo período), 3 (terceiro período) e 4 (quarto período); $\varepsilon_{\mathrm{i}}$, à variação aleatória residual.

A interação entre tratamento e bloco $(\tau * \beta)$ inicialmente testada foi retirada do modelo estatístico final, devido à sua não-significância $(\mathrm{P}=0,05)$. As análises estatísticas foram realizadas, utilizando-se o pacote estatístico SAS (SAS, 1997).

\section{Resultados e Discussão}

Na Tabela 1, são apresentadas as precipitações pluviométricas ocorridas e normais correspondentes aos meses em que foram conduzidas as lavouras dos diferentes híbridos.

Verifica-se, na Tabela 1, que a precipitação nos meses de dezembro e fevereiro esteve abaixo do normal, o que afetou o desenvolvimento inicial dos híbridos e a produção de grãos.

As médias da avaliação do comportamento produtivo da planta dos híbridos de milho são apresentados na Tabela 2.

O ciclo produtivo dos diferentes materiais genéticos foi definido no momento da colheita das lavouras para o processo de ensilagem, constatando-se maior precocidade ao híbrido C-806 com 100 dias de intervalo da semeadura (15/12/99) à colheita (24/03/00), comparado ao AG-5011 colhido em 07/04/00 (114 dias) e ao XL-344 colhido em 14/04/00 (121 dias).

Verifica-se na Tabela 2 que o híbrido AG-5011 apresentou altura de planta superior, quando comparado aos outros materiais avaliados, o que resultou, entre outros fatores, em maior potencial produtivo de matéria verde e matéria seca ensilável por unidade de área, além de apresentar também altura de inserção de espiga superior em relação aos demais híbridos ( $\mathrm{P}<0,05)$. Almeida Filho et al. (1999), conduzindo trabalho de avaliação de milho para silagens, em que foram testados 19 cultivares em parcelas, encontraram variação para altura de plantas entre 1,50 e 1,98 m, correlacionando-se positivamente com produções de matéria seca variando entre 10,35 e 12,72 t/ha. Silva et al. (1999a), avaliando o potencial produtivo de forragens, encontraram para o híbrido AG-5011 altura de 2,33 m e produção de MS de 10,28 t/ha.

Analisando-se os resultados quanto à população final, observa-se menor população $(\mathrm{P}<0,05)$ para o

Tabela 1 - Precipitação pluviométrica $(\mathrm{mm})$ ocorrida e normal, referentes ao período de Novembro/ 99 a Abril/00

Table 1 - Rainfall $(\mathrm{mm})$ occured and normal, regarding the period of November/99 April/00

\begin{tabular}{lcccccc}
\hline $\begin{array}{l}\text { Período } \\
\text { Period }\end{array}$ & $\begin{array}{c}\text { Novembro } \\
\text { November }\end{array}$ & $\begin{array}{c}\text { Dezembro } \\
\text { December }\end{array}$ & $\begin{array}{c}\text { Janeiro } \\
\text { January }\end{array}$ & $\begin{array}{c}\text { Fevereiro } \\
\text { February }\end{array}$ & $\begin{array}{c}\text { Março } \\
\text { March }\end{array}$ & $\begin{array}{c}\text { Abril } \\
\text { April }\end{array}$ \\
\hline $\begin{array}{l}\text { Ocorrida 1999-2000 } \\
\begin{array}{l}\text { Occured 1999-2000 } \\
\text { Normal }\end{array}\end{array}$ & 75,2 & 83,1 & 246,0 & 90,5 & 248,9 & 78,2 \\
Normal & 132,2 & 133,5 & 145,1 & 130,2 & 151,7 & 134,7 \\
\hline
\end{tabular}

R. Bras. Zootec., v.33, n.2, p.302-312, 2004 
híbrido XL-344, quando comparado aos demais híbridos. O número de sementes plantadas por hectare foi de 61.111, objetivando uma população final de 50.000 plantas/ha. No entanto, em decorrência de particularidades do ano agrícola 1999/2000, que apresentou instabilidade climática, principalmente sobre o regime hídrico (Tabela 1) da Região Centro-Oeste do Rio Grande do Sul, o que interferiu de maneira negativa sobre o estádio inicial de desenvolvimento das lavouras, ocorreram em populações inferiores ao preconizado em todos os híbridos. A menor população do híbrido XL-344 indica que este material foi mais sensível ao déficit hídrico que o AG-5011 e C-806.

$\mathrm{Na}$ Tabela 3, é apresentada a participação percentual das diversas partes da planta de diferentes híbridos de milho, com base na matéria seca (MS).

Constata-se, na Tabela 3, que o híbrido C-806 apresentou maiores quantidades de colmo e folhas e menor quantidade de espigas que o AG-5011 e XL-344, que não diferiram entre si. A participação da espiga nos três híbridos ficou abaixo dos 64-65\%, considerado por Nussio (1991) como o ideal. Avaliando a participação do grão, que é o componente mais importante em função da concentração energética, constata-se que esta foi menor no C-806. A quantidade de grãos dos três híbridos esteve abaixo dos $40 \%$ considerado pela maioria dos autores como o ideal para produção da silagem de alta qualidade (Nussio, 1999; Brondani et al., 2000; Keplin, 2001). Sabe-se que a cultura do milho é muito exigente em água, principalmente na época de florescimento e formação dos grãos. Considerando a restrição hídrica observada no período de condução do trabalho, observou-se que a menor concentração de grãos foi no C-806.

Os teores de matéria seca parcial da planta e de seus componentes, de acordo com o híbrido de milho testado, são apresentados na Tabela 4.

Os teores de MSp da planta inteira e dos componentes colmo e folhas verdes no momento da ensilagem das plantas foram semelhantes $(\mathrm{P}=0,05)$ entre os híbridos. O híbrido AG-5011 apresentou maior teor de MSp $(\mathrm{P}<0,05)$ para espiga e grão em relação ao híbrido XL-344, que, por sua vez, foi maior $(\mathrm{P}<0,05)$ que o híbrido C-806. O híbrido C-806 apresentou também menor teor de MSp $(\mathrm{P}<0,05)$ para o componente pendão em relação aos demais híbridos avaliados.

$\mathrm{Na}$ análise dos componentes da planta, os maiores teores de MSp foram observados nos componentes pendão, grão e espiga, independentemente do híbrido avaliado. O grão é o componente que normalmente exerce a maior influência sobre o teor de MS da planta, por sua maior participação física e menor teor de umidade.

Segundo Silva et al. (1999b), os teores de matéria seca dos componentes da planta são variáveis conforme a interação genótipo ambiente, atuando sobre o acúmulo de matéria seca da planta inteira. Por outro lado, Nussio (1991), analisando equações de regressão entre os parâmetros agronômicos de 18 híbridos de milho, de ciclo precoce e normal, para produção de silagem, definiu que o aumento da porcentagem de

Tabela 2 - Comportamento agronômico de híbridos de milho para produção de silagem Table 2 - Agronomic behavior of corn hybrids for silage production

\begin{tabular}{|c|c|c|c|c|c|c|}
\hline \multirow{2}{*}{$\begin{array}{l}\text { Parâmetros } \\
\text { Parameters }\end{array}$} & \multicolumn{3}{|c|}{$\begin{array}{c}\text { Híbridos de milho } \\
\text { Corn hybrids }\end{array}$} & \multirow{2}{*}{$\begin{array}{l}\text { Teste } \mathrm{F} \\
\text { F test }\end{array}$} & \multirow[t]{2}{*}{$\mathrm{P}<$} & \multirow[t]{2}{*}{$\mathrm{CV}(\%)$} \\
\hline & AG-5011 & XL-344 & C-806 & & & \\
\hline $\begin{array}{l}\text { Ciclo, dias } \\
\text { Cycle, davs }\end{array}$ & 114 & 121 & 100 & - & - & - \\
\hline $\begin{array}{l}\text { Altura da planta, m } \\
\text { Plant height, } m\end{array}$ & $1,84^{\mathrm{a}}$ & $1,66^{\mathrm{b}}$ & $1,69^{b}$ & 76,53 & 0,0001 & 2,90 \\
\hline $\begin{array}{l}\text { Altura da espiga, m } \\
\text { Ear height, } m\end{array}$ & $1,03^{\mathrm{a}}$ & $0,75^{\mathrm{c}}$ & $0,84^{\mathrm{b}}$ & 65,48 & 0,0001 & 8,97 \\
\hline $\begin{array}{l}\text { População, plantas/ha } \\
\text { Population, plant/ha }\end{array}$ & $39259^{a}$ & $33889^{b}$ & $41667^{a}$ & 24,77 & 0,0013 & 9,35 \\
\hline $\begin{array}{l}\text { Produção de matéria verde, } \mathrm{kg} / \mathrm{ha} \\
\text { Fresh matter production, } \mathrm{kg} / \mathrm{ha}\end{array}$ & $38144^{\mathrm{a}}$ & $26654^{b}$ & $29855^{\mathrm{b}}$ & 62,60 & 0,0001 & 10,62 \\
\hline $\begin{array}{l}\text { Produção matéria seca ensilável, } \mathrm{kg} / \mathrm{ha} \\
\text { Dry matter production for silage, } \mathrm{kg} / \mathrm{ha}\end{array}$ & $12471^{\mathrm{a}}$ & $7201^{b}$ & $8150^{\mathrm{b}}$ & 137,08 & 0,0001 & 19,21 \\
\hline
\end{tabular}

Médias, na mesma linha, seguidas de letras diferentes, diferem entre si pelo teste Tukey $(P<0,05)$.

Average, within a row, followed by different letters, are diferent $(P<.05)$ by Tukey test. 
grãos na MS está vinculado à menor produção de matéria seca por unidade de área em materiais de ciclo precoce, da mesma forma que estes materiais apresentam maior teor de MS no momento do corte.

Os componentes da parede celular, FDN, FDA, HEM, CEL e LIG da silagem dos diferentes híbridos de milho, com base na MS, são apresentados na Tabela 5.

Observa-se que os teores médios de FDN, FDA, HEM, CEL e LIG não apresentaram diferença $(\mathrm{P}=0,05)$ para as silagens dos diferentes híbridos avaliados.

O teor de FDN é indicativo da quantidade total de fibra do volumoso, estando diretamente relacionada ao consumo pelos animais. Os teores de FDN das silagens variaram entre 55,76 e $57,99 \%$. Estes valores são superiores aos citados por Costa et al. (2000), que, analisando 12 cultivares de milho na EMBRAPACNPGL, encontraram variação entre 48,23 e 55,40\%, e inferiores aos descritos por Almeida Filho et al. (1999), com variação entre 58,13 e 63,39\%.

Os teores de FDA, que indicam a digestibilidade da silagem por apresentar maior proporção de lignina (fração não digestível) e celulose encontrada nos materiais $(26,92$ a $28,92 \%)$, foram inferiores aos relatados por Almeida Filho et al. (1999) (28,89 a $31,75 \%)$ e por Costa et al. (2000) (26,32 a 33,95\%).

A explicação da variação dos teores da fração fibrosa da planta poderia estar na análise dos cortes histológicos do colmo destes materiais com características de comportamento agronômico diferenciado, com a identificação de agrupamento de células de menor ou maior tamanho individual, resultante de programas de melhoramento genético, quanto à resistência do colmo ao acamamento e agentes patógenos (Nussio, 1999).

Os parâmetros relativos à qualidade das silagens avaliadas são apresentados na Tabela 6.

Os teores de MS das silagens diferiram $(\mathrm{P}<0,05)$ entre os genótipos avaliados, observando o maior teor para o híbrido AG-5011 com 30,69\% em relação aos híbridos XL-344 (25,84\%) e C-806 (25,77\%). Esperava-se maior teor de MS que o observado nos híbridos XL-344 e C-806. No entanto, a determinação do ponto de colheita baseou-se apenas no estádio do grão, sem levar em consideração as variações quanto aos demais componentes da planta, como a maturidade das folhas e o conteúdo de água no colmo. Além disso, no momento da colheita, as plantas

Tabela 3 - Participação porcentual das diversas partes da planta de diferentes híbridos de milho, com base na matéria seca (MS)

Table 3 - Percentile participation of the several parts of the plant of different corn hybrids, based on dry matter (DM)

\begin{tabular}{|c|c|c|c|c|c|c|}
\hline \multirow{2}{*}{$\begin{array}{l}\text { Parâmetros } \\
\text { Parameters }\end{array}$} & \multicolumn{3}{|c|}{$\begin{array}{l}\text { Híbridos de milho } \\
\text { Corn hybrids }\end{array}$} & \multirow{2}{*}{$\begin{array}{l}\text { Teste } \mathrm{F} \\
\text { F test }\end{array}$} & \multirow{2}{*}{$P<$} & \multirow{2}{*}{$C V(\%)$} \\
\hline & AG-5011 & XL-344 & C-806 & & & \\
\hline \multicolumn{7}{|c|}{$\begin{array}{c}\text { Participação das diversas partes da planta (\% MS) } \\
\text { Participation of the several parts of the plant }(\% \text { DM) }\end{array}$} \\
\hline $\begin{array}{l}\text { Colmo } \\
\text { Stem }\end{array}$ & $24,9^{\mathrm{b}}$ & $22,7^{b}$ & $28,5^{\mathrm{a}}$ & 23,41 & 0,0001 & 10,55 \\
\hline $\begin{array}{l}\text { Folhas } \\
\text { Leaves }\end{array}$ & $19,6^{\mathrm{b}}$ & $19,0^{\mathrm{b}}$ & $24,6^{\mathrm{a}}$ & 17,01 & 0,0034 & 11,44 \\
\hline $\begin{array}{l}\text { Verdes } \\
\text { Green }\end{array}$ & $17,4^{\mathrm{b}}$ & $16,0^{\mathrm{b}}$ & $24,6^{\mathrm{a}}$ & 42,19 & 0,0003 & 18,33 \\
\hline $\begin{array}{l}\text { Secas } \\
\text { Dry }\end{array}$ & 2,2 & 3,0 & - & 5,09 & 0,0871 & 29,85 \\
\hline $\begin{array}{l}\text { Espiga } \\
\text { Ear }\end{array}$ & $54,6^{\mathrm{a}}$ & $57,4^{\mathrm{a}}$ & $45,8^{\mathrm{b}}$ & 22,43 & 0,0016 & 6,61 \\
\hline $\begin{array}{l}\text { Grão } \\
\text { Grain }\end{array}$ & $33,4^{\mathrm{a}}$ & $35,0^{\mathrm{a}}$ & $20,1^{\mathrm{b}}$ & 51,16 & 0,0002 & 17,02 \\
\hline $\begin{array}{l}\text { Sabugo } \\
\mathrm{Cob}\end{array}$ & $10,6^{\mathrm{b}}$ & $10,1^{\mathrm{b}}$ & $12,5^{\mathrm{a}}$ & 30,03 & 0,0007 & 9,47 \\
\hline $\begin{array}{l}\text { Palha } \\
\text { Straw }\end{array}$ & 10,6 & 12,3 & 13,3 & 2,92 & 0,1300 & 20,46 \\
\hline $\begin{array}{l}\text { Pendão } \\
\text { Pennant }\end{array}$ & 0,9 & 0,9 & 1,1 & 2,77 & 0,1404 & 20,16 \\
\hline
\end{tabular}

Médias, na mesma linha, seguidas de letras diferentes, diferem entre si pelo teste Tukey $(\mathrm{P}<0,05)$.

Average, within a row, followed by different letters, are different $(P<.05)$ by Tukey test.

R. Bras. Zootec., v.33, n.2, p.302-312, 2004 
apresentaram certa desuniformidade quanto ao estádio de desenvolvimento, pois a germinação não ocorreu de maneira uniforme, em função do déficit hídrico. Este aspecto foi mais evidente no híbrido XL-344. Com base nos teores de MS da silagem, conforme Borges et al. (1997), a silagem do híbrido AG-5011 é classificada como de muito boa qualidade, enquanto as demais, como de boa qualidade.

O teor de matéria seca influencia a intensidade do processo de fermentação da silagem (Van Soest, 1994). Segundo Mühlbach (1999), o menor teor de umidade, associado à maior tensão osmótica, decorrente da concentração de nutrientes, inibe o surgimento de fermentações indesejáveis, causadas por bactérias clostrídicas, sem prejudicar a fermentação láctica. Para melhor preservação de forragens com teores de MS abaixo de $30 \%$, é necessário maior acidez $(\mathrm{pH}<4,0)$, enquanto, para materiais mais secos (MS>40\%), a fermentação é menos intensa e, conseqüentemente, o pH final é mais elevado ( $\mathrm{pH}>4,5)$.

Segundo alguns autores (Van Soest, 1994; Nussio, 1999; Brondani et al., 2000), o teor de MS ideal para ensilagem seria entre 30 e $35 \%$, com objetivo de evitar perdas pela formação de efluentes e processos biológicos que produzam gases, água e calor, visando adequada fermentação láctica para manutenção do valor nutritivo da silagem. No entanto, no presente trabalho, não foram verificadas perdas de líquidos na silagem dos três híbridos avaliados, embora o teor de MS tenha sido 25,84 e $25,77 \%$, nas silagens do XL-344 e C-806, respectivamente.

Não houve diferença $(P=0,05)$ no teor de $P B$ entre as silagens avaliadas, sendo que os teores de PB variaram entre 9,26 e 9,74\%. Estes valores foram similares aos relatados por Andrade et al. (1998), que, avaliando silagem de sete cultivares de milho, encontraram valor médio de $9,17 \%$ de $\mathrm{PB}$, tendo o híbrido AG-5011 apresentado o maior valor com 9,83\% de PB.

Os teores de MM das silagens diferiram $(\mathrm{P}<0,05)$ entre os híbridos avaliados, observando o maior teor de MM para o XL-344 (4,55\%) e o menor para o AG-5011 (3,61\%). Berto et al. (1998) encontraram valores similares, avaliando silagens de 34 unidades de produção leiteira no Rio Grande do Sul, que apresentaram teor médio de 3,92\% de MM.

Não houve diferença $(\mathrm{P}=0,05)$ para os teores de EE, FB e DIVMS entre as silagens dos híbridos avaliados, apresentando teor médio de 4,68\% para

Tabela 4 - Teores de matéria seca parcial (MSp) da planta inteira e de seus componentes físicos, de acordo com os diferentes híbridos de milho

Table 4 - Contents of partial dry matter (DMp) of the whole plant and physical components, according to the different corn hybrids

\begin{tabular}{|c|c|c|c|c|c|c|}
\hline \multirow{2}{*}{$\begin{array}{l}\text { Parâmetros } \\
\text { Parameters }\end{array}$} & \multicolumn{3}{|c|}{$\begin{array}{l}\text { Híbridos de milho } \\
\text { Corn hybrids }\end{array}$} & \multirow{3}{*}{$\begin{array}{l}\text { Teste F } \\
\text { F test }\end{array}$} & \multirow[t]{3}{*}{$P<$} & \multirow[t]{2}{*}{$C V(\%)$} \\
\hline & AG-5011 & XL-344 & C-806 & & & \\
\hline \multicolumn{5}{|c|}{$\% \mathrm{MSp} \quad(\% D M p)$} & & \\
\hline $\begin{array}{l}\text { Planta } \\
\text { Plant }\end{array}$ & 35,53 & 29,62 & 29,42 & 6,99 & 0,0742 & 5,89 \\
\hline $\begin{array}{l}\text { Colmo } \\
\text { Stem }\end{array}$ & 23,28 & 20,26 & 28,51 & 5,25 & 0,1048 & 10,73 \\
\hline $\begin{array}{l}\text { Folhas verdes } \\
\text { Green leaves }\end{array}$ & 31,58 & 24,95 & 26,28 & 4,72 & 0,1184 & 8,27 \\
\hline $\begin{array}{l}\text { Folhas secas } \\
\text { Dry leaves }\end{array}$ & 49,60 & 27,81 & - & 4,11 & 0,1797 & 27,76 \\
\hline $\begin{array}{l}\text { Espiga } \\
\text { Ear }\end{array}$ & $49,22^{\mathrm{a}}$ & $38,47^{b}$ & $33,30^{\mathrm{c}}$ & 148,06 & 0,0010 & 2,34 \\
\hline $\begin{array}{l}\text { Grão } \\
\text { Grain }\end{array}$ & $59,28^{\mathrm{a}}$ & $50,44^{\mathrm{b}}$ & $42,13^{c}$ & 125,07 & 0,0013 & 2,14 \\
\hline $\begin{array}{l}\text { Sabugo } \\
\text { Cob }\end{array}$ & 40,98 & 33,79 & 32,10 & 7,28 & 0,0706 & 6,94 \\
\hline $\begin{array}{l}\text { Palha } \\
\text { Straw }\end{array}$ & 36,90 & 25,08 & 25,86 & 10,86 & 0,0423 & 9,69 \\
\hline $\begin{array}{l}\text { Pendão } \\
\text { Pennant }\end{array}$ & $69,70^{\mathrm{a}}$ & $56,43^{\mathrm{ab}}$ & $50,76^{\mathrm{b}}$ & 15,86 & 0,0254 & 5,85 \\
\hline
\end{tabular}

Médias, na mesma linha, seguidas de letras diferentes, diferem entre si pelo teste Tukey $(P<0,05)$.

Average, within a row, followed by different letters, are different $(P<.05)$ by Tukey test.

R. Bras. Zootec., v.33, n.2, p.302-312, 2004 
EE, $21,15 \%$ para FB e DIVMS média de 58,47\%, sendo avaliadas segundo a classificação de Borges et al. (1997), com base nos teores de DIVMS, como silagens de boa qualidade. Estes valores são superiores aos relatados por Almeida Filho et al. (1999), que encontraram valores entre 53,15 e 56,86\% avaliando 19 cultivares de milho.

$\mathrm{Na}$ Tabela 7, são apresentados os parâmetros relativos ao valor nutritivo da silagem dos diferentes híbridos de milho.
Os teores de $\mathrm{MO}$ das silagens diferiram $(\mathrm{P}<0,05)$ entre os híbridos, observando-se o maior teor de MO para o AG-5011 (96,39\%) e o menor, para o XL-344 $(95,45 \%)$, podendo ser explicado pelas características fenotípicas dos híbridos avaliados, em que os percentuais dos componentes estruturais da planta de milho variaram conforme o comportamento produtivo dos mesmos. Não houve diferença $(\mathrm{P}=0,05)$ entre as silagens quanto aos teores de DIVMO e MOD, que apresentaram teor médio de $60,54 \%$ e $58,01 \mathrm{~g}$, respectivamente.

Tabela 5 - Teores de fibra em detergente neutro (FDN), hemicelulose (HEM), fibra em detergente ácido (FDA), celulose $(C E L)$ e lignina (LIG) de silagens de diferentes híbridos de milho

Table 5 - Contents of neutral detergent fiber (NDF), hemicellulose (HEM), acid detergent fiber (ADF), cellulose (CEL) and lignin (LIG) of silages of different corn hybrids

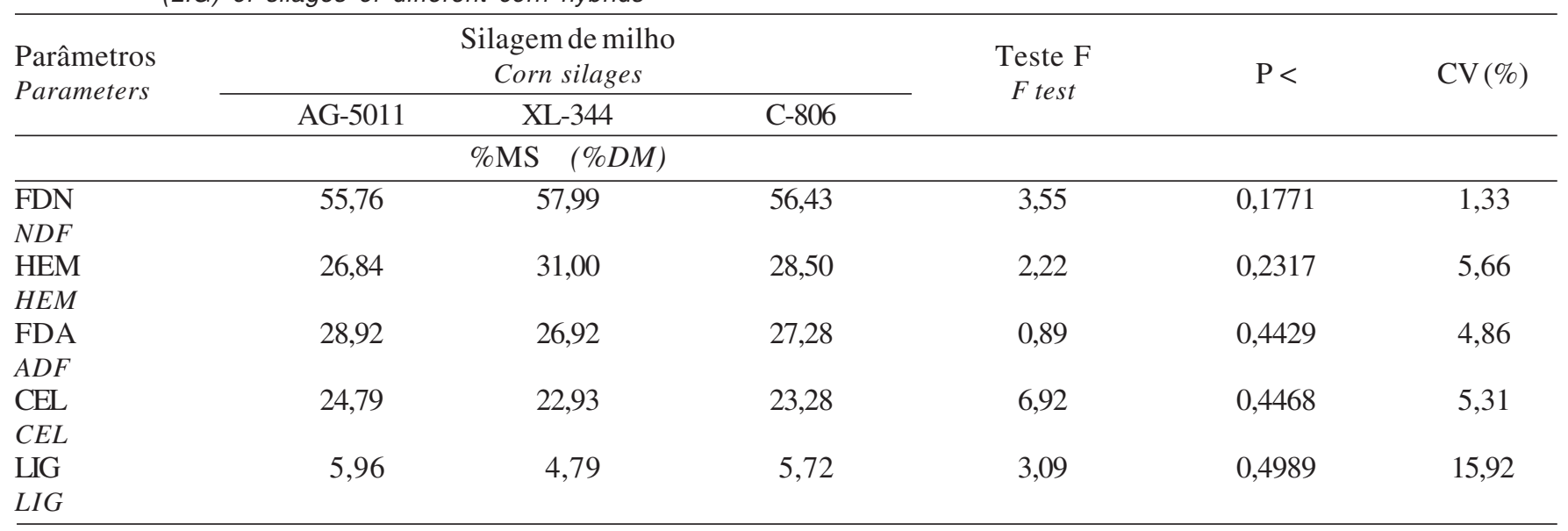

Tabela 6 - Teores de matéria seca (MS), proteína bruta (PB), matéria mineral (MM), extrato etéreo (EE), fibra bruta (FB), e digestibilidade in vitro da matéria seca (DIVMS) de silagens de diferentes híbridos de milho

Table 6 - Contents of dry matter (DM), crude protein (CP), mineral matter (MM) ether extract (EE), crude fiber (CF), and in vitro dry matter digestibility (IVDMD), of silages of different corn hybrids

\begin{tabular}{|c|c|c|c|c|c|c|}
\hline \multirow{2}{*}{$\begin{array}{l}\text { Parâmetros } \\
\text { Parameters }\end{array}$} & \multicolumn{3}{|c|}{$\begin{array}{l}\text { Silagem de milho } \\
\text { Corn silages }\end{array}$} & \multirow{2}{*}{$\begin{array}{c}\text { Teste F } \\
\text { F test }\end{array}$} & \multirow[t]{2}{*}{$\mathrm{P}<$} & \multirow[t]{2}{*}{$\mathrm{CV}(\%)$} \\
\hline & AG-5011 & XL-344 & C-806 & & & \\
\hline \multicolumn{7}{|c|}{$\%$} \\
\hline MS & $30,69^{a}$ & $25,84^{b}$ & $25,77^{\mathrm{b}}$ & 17,09 & 0,0001 & 3,55 \\
\hline \multirow{3}{*}{$\begin{array}{l}D M \\
\text { DIVMS } \\
I V D M D\end{array}$} & & & & & & \\
\hline & 57,82 & 60,00 & 57,59 & 3,65 & 0,3032 & 3,75 \\
\hline & \multicolumn{3}{|c|}{$\% \mathrm{MS}(\% D M)$} & & & \\
\hline PB & 9,33 & 9,26 & 9,74 & 2,82 & 0,3983 & 6,05 \\
\hline \multicolumn{7}{|l|}{$C P$} \\
\hline MM & $3,61^{b}$ & $4,55^{\mathrm{a}}$ & $4,37^{\mathrm{ab}}$ & 2,31 & 0,0291 & 14,37 \\
\hline $\mathrm{EE}$ & 4,57 & 4,84 & 4,63 & 4,09 & 0,2483 & 2,45 \\
\hline $\mathrm{FB}$ & 22,56 & 20,30 & 20,58 & 2,85 & 0,7024 & 16,22 \\
\hline$C F$ & & & & & & \\
\hline
\end{tabular}

Médias, na mesma linha, seguidas de letras diferentes, diferem entre si pelo teste Tukey $(\mathrm{P}<0,05)$. Average, within a row, followed by different letters, are different $(P<.05)$ by Tukey test.

R. Bras. Zootec., v.33, n.2, p.302-312, 2004 
Não foi observada diferença $(\mathrm{P}=0,05)$ entre os híbridos para NDT e a concentração de energia metabolizável e energia líquida para mantença e ganho.

Na comparação das silagens avaliadas, os teores médios de NDT apresentados foram de 69,12\%, superiores aos relatados por Pimentel et al. (1998), que observaram valores entre 62,50 e $63,87 \%$ de NDT, indicando qualidade superior destes materiais quanto ao seu valor energético. Rosa et al. (2004) confirmaram a qualidade destes materiais, por meio do desempenho em confinamento de machos nãocastrados, que receberam as silagens dos híbridos AG-5011, XL-344 e C-806, em uma relação volumoso:concentrado 70:30, promovendo ganho médio diário de 1,283; 1,219; e 1,249 kg/dia e conversão alimentar de 5,26; 4,98; e 4,97, respectivamente.

Os teores de $\mathrm{pH}$ e nitrogênio amoniacal no nitrogênio total $\left(\mathrm{N}-\mathrm{NH}_{3} / \mathrm{NT}\right)$ da silagem dos híbridos avaliados estão descritos na Tabela 8.

Não houve diferença $(\mathrm{P}=0,05)$ entre o $\mathrm{pH}$ das silagens, sendo que a média dos valores encontrados foi de 3,41. Mesmo sem conhecimento da velocidade de queda do $\mathrm{pH}$ durante o processo de fermentação, estes materiais podem ser classificados com base neste critério, de acordo com Borges et al. (1997), como silagens de muito boa qualidade.

$\mathrm{Na}$ análise dos teores de $\mathrm{N}$-amoniacal, houve diferença $(\mathrm{P}<0,05)$ entre os híbridos avaliados. A silagem do híbrido XL-344 apresentou o maior teor de $\mathrm{N}-\mathrm{NH}_{3} / \mathrm{NT}(8,03 \%)$, diferindo dos híbridos AG-5011 $(5,43 \%)$ e C-806 (5,22\%). Apesar da diferença, os teores médios de $\mathrm{NH}_{3}$ das silagens permaneceram abaixo de $10 \%$ do $\mathrm{N}$ total, indicando que houve fermentação láctica adequada. Neste critério, os materiais avaliados podem ser classificados como silagem de muito boa qualidade, segundo Borges et al. (1997).

$\mathrm{O} \mathrm{N}$-amoniacal, expresso em porcentagem do $\mathrm{N}$ total, indica a quantidade de proteína degradada durante a fase de fermentação, ou ainda a ocorrência de um aquecimento excessivo na massa do silo. Este calor excessivo, na presença de açúcares e nitrogênio, pode levar à 'reação de Maillard', ocasionando a

Tabela 7 - Teores de matéria orgânica (MO), matéria orgânica digestível (MOD), digestibilidade in vitro da matéria orgânica (DIVMO), nutrientes digestíveis totais (NDT), energia digestível (ED), energia metabolizável (EM), energia líquida de mantença $\left(\mathrm{EI}_{\mathrm{m}}\right)$, e energia líquida de ganho $\left(\mathrm{EI}_{\mathrm{g}}\right)$, da silagem dos diferentes híbridos de milho

Table 7 - Contents of organic matter (OM), digestible organic matter (DOM), in vitro organic matter digestibility (IVOMD), total digestible nutrients (TDN), digestible energy (DE), metabolizable energy (ME), net energy for maintenance $\left(N E_{m}\right)$, and net energy for gain $\left(N E_{g}\right)$ of silages of different corn hybrids

\begin{tabular}{|c|c|c|c|c|c|c|}
\hline \multirow{2}{*}{$\begin{array}{l}\text { Parâmetros } \\
\text { Parameters }\end{array}$} & \multicolumn{3}{|c|}{$\begin{array}{l}\text { Silagem de milho } \\
\text { Corn silages }\end{array}$} & \multirow{2}{*}{$\begin{array}{l}\text { Teste } \mathrm{F} \\
\text { F test }\end{array}$} & \multirow[t]{2}{*}{$\mathrm{P}<$} & \multirow[t]{2}{*}{$\mathrm{CV}(\%)$} \\
\hline & AG-5011 & XL-344 & C-806 & & & \\
\hline \multicolumn{7}{|c|}{$\% \mathrm{MS}(\% D M)$} \\
\hline $\mathrm{MO}$ & $96,39^{\mathrm{a}}$ & $95,45^{\mathrm{b}}$ & $95,63^{\mathrm{ab}}$ & 2,31 & 0,0291 & 0,63 \\
\hline $\begin{array}{l}O M \\
\text { MOD } \\
D O M\end{array}$ & 57,25 & 59,79 & 56,99 & 2,13 & 0,2087 & 3,73 \\
\hline $\begin{array}{l}\text { DIVMO } \\
\text { IVOMD }\end{array}$ & 59,39 & 62,64 & 59,60 & 2,82 & 0,1299 & 3,52 \\
\hline $\begin{array}{l}\text { NDT } \\
T D N \\
\end{array}$ & 68,62 & 69,39 & 69,35 & 1,89 & 0,2376 & 3,63 \\
\hline \multicolumn{7}{|c|}{$\mathrm{Mcal} / \mathrm{kg}$ de MS (Mcal/kg of DM) } \\
\hline $\begin{array}{l}\mathrm{ED} \\
D E\end{array}$ & 2,600 & 2,716 & 2,588 & 2,13 & 0,2078 & 3,73 \\
\hline $\begin{array}{l}\mathrm{EM} \\
M E\end{array}$ & 2,132 & 2,227 & 2,122 & 2,14 & 0,2072 & 3,72 \\
\hline $\begin{array}{l}\text { Elm } \\
N E_{m}\end{array}$ & 1,274 & 1,362 & 1,266 & 2,14 & 0,2063 & 5,67 \\
\hline $\begin{array}{l}\mathrm{Elg} \\
N E_{g} \\
\end{array}$ & 0,703 & 0,783 & 0,696 & 2,15 & 0,2065 & 9,21 \\
\hline
\end{tabular}

Médias, na mesma linha, seguidas de letras diferentes, diferem entre si pelo teste Tukey $(\mathrm{P}<0,05)$. Average, within a row, followed by different letters, are different $(P<.05)$ by Tukey test.

R. Bras. Zootec., v.33, n.2, p.302-312, 2004 
Tabela 8 - Teores de nitrogênio amoniacal $\left(\mathrm{N}-\mathrm{NH}_{3} / \mathrm{NT}, \%\right.$ do $\mathrm{N}$ total) e $\mathrm{pH}$ de silagens de diferentes híbridos de milho Table 8 - Contents of ammonia nitrogen $\left(\mathrm{N}^{-\mathrm{NH}_{3}}\right.$, \% of total $\left.\mathrm{N}\right)$ and $\mathrm{pH}$ of silages of different corn hybrids

\begin{tabular}{|c|c|c|c|c|c|c|}
\hline \multirow{2}{*}{$\begin{array}{l}\text { Parâmetros } \\
\text { Parameters }\end{array}$} & \multicolumn{3}{|c|}{$\begin{array}{l}\text { Silagem de milho } \\
\text { Corn silages }\end{array}$} & \multirow{2}{*}{$\begin{array}{l}\text { Teste } \mathrm{F} \\
\text { F test }\end{array}$} & \multirow[t]{2}{*}{$\mathrm{P}<$} & \multirow[t]{2}{*}{$\mathrm{CV}(\%)$} \\
\hline & AG-5011 & XL-344 & C-806 & & & \\
\hline $\begin{array}{l}\mathrm{N}-\mathrm{NH}_{3} / \mathrm{NT}(\%) \\
\mathrm{N}-\mathrm{NH}_{3}\end{array}$ & $5,43^{\mathrm{b}}$ & $8,03^{\mathrm{a}}$ & $5,22^{\mathrm{b}}$ & 37,17 & 0,0095 & 3,63 \\
\hline $\begin{array}{l}\mathrm{pH} \\
\mathrm{pH}\end{array}$ & 3,41 & 3,45 & 3,38 & 0,13 & 0,9514 & 5,97 \\
\hline
\end{tabular}

Médias, na mesma linha, seguidas de letras diferentes, diferem entre si pelo teste Tukey $(P<0,05)$.

Average, within a row, followed by different letters, are different $(P<.05)$ by Tukey test.

reação dos açúcares com a proteína, formando substâncias contendo nitrogênio indisponíveis ao animal (Van Soest, 1994).

Portanto, este parâmetro é um dos principais na determinação da qualidade do processo fermentativo da massa ensilada. Segundo McDonald et al. (1991), silagens mal preservadas apresentam níveis de amônia superiores a $10 \%$, sendo a amônia derivada do catabolismo de aminoácidos, entre outros produtos de degradação como aminas, cetoácidos e ácidos graxos, por via de três processos bioquímicos: deaminação, descarboxilação e reações de oxidação e redução.

Cabe ressaltar ainda que, embora os teores de umidade da silagem do XL-344 e C-806 tenham sido muito similares, ocorreu diferença significativa no teor do $\mathrm{N}-\mathrm{NH}_{3} / \mathrm{NT}$. Esta constatação indica que, além do conteúdo de água, há outros fatores envolvidos no processo de produção de amônia.

\section{Conclusões}

As características fenotípicas da planta de milho determinaram o potencial produtivo das silagens, tendo o híbrido AG-5011 apresentado a maior altura de planta e potencial produtivo de matéria verde e matéria seca ensilável por área, em relação aos híbridos C-806 e XL-344.

Com base nos teores de MS e DIVMS, as silagens dos híbridos AG-5011, C-806 e XL-344 são classificadas como de boa qualidade e, com relação às características fermentativas, $\mathrm{N}-\mathrm{NH}_{3} / \mathrm{NT}$ e $\mathrm{pH}$, as silagens avaliadas são classificadas como de excelente qualidade.

\section{Literatura Citada}

AGRICULTURAL RESEARCH CONCIL - ARC. The nutrients requirements of ruminants livestock. Technical review by on Agricultural Research Council working Patry, London, 1980. 351p.

ALMEIDA FILHO, S.L.; FONSECA, D.M.; GARCIA, R. et al. Características agronômicas de cultivares de milho (Zea mays L.) e qualidade dos componentes e da silagem. Revista Brasileira de Zootecnia, v.28, n.1, p.7-13, 1999.

ANDRADE, J.B.; HENRIQUE, W.; BRAUN, G. et al. Produção de silagem e reciclagem de nutrientes em sete cultivares de milho. 1 - Composição bromatológica. In: REUNIÃO ANUAL DA SOCIEDADE BRASILEIRA DE ZOOTECNIA, 35., 1998, Botucatu. Anais... Botucatu: Sociedade Brasileira de Zootecnia, 1998. p.218-220.

ASSOCIATION OF OFFICIAL ANALYTICAL CHEMIST AOAC. Official methods of analysis. 14.ed. Washington, D.C.: $1984.1141 \mathrm{p}$.

ASSOCIATION OF OFFICIAL ANALYTICAL CHEMIST AOAC Official methods of analysis. 16.ed. Washington, D.C., 1995. 1094p.

BERTO, J.L.; MÜHLBACH, P.R.F.; SANTOS, A.C. Qualidade da silagem de milho em unidades de produção de leite no Rio Grande do Sul. In: REUNIÃO ANUAL DA SOCIEDADE BRASILEIRA DEZOOTECNIA, 35., 1998, Botucatu. Anais... Botucatu: Sociedade Brasileira de Zootecnia, 1998. p.206-208.

BORGES, A.L.C.C.; GONÇALVES, L.C.; RODRIQUEZ, N.M. et al. Qualidade de silagens de híbridos de sorgo de porte alto, com diferentes teores de tanino e umidade no colmo. Pesquisa Brasileira Medicina Veterinária e Zootecnia, v.49, n.4, p.441-452, 1997.

BRONDANI, I.L.; ALVES FILHO, D.C.; BERNARDES, R.A.C. Silagem de alta qualidade para bovinos. In: RESTLE, J. (Ed.) Eficiência na produção de bovinos de corte. Santa Maria: Universidade Federal de Santa Maria, 2000. p.147-184.

COSTA, R.S.; GONÇALVES, L.C.; RODRIGUES, J.A.S. et al. Composição química da planta verde e das silagens de doze cultivares de milho. In: REUNIÃO ANUAL DA SOCIEDADE BRASILEIRA DE ZOOTECNIA, 37., 2000, Viçosa, MG Anais... Viçosa: Sociedade Brasileira de Zootecnia, 2000. p.56. 
DNPEA-BRASIL. Ministério da Agricultura. Departamento Regional de Pesquisa Agropecuária: Divisão de Pesquisas Pedológicas, 1973. (Boletim Técnico, 30) Levantamento de reconhecimento de solos do Rio Grande do Sul. Rio de Janeiro. 431p.

EMBRAPA-CNPT. SBCS - Núcleo Regional Sul. Recomendações de adubação e calagem para os Estados do Rio Grande do Sul e Santa Catarina. 3.ed. Passo Fundo: EMBRAPA-CNPT, 1995. 224p.

GOERING, H.K.; Van SOEST, P.J. Forage fiber analysis: apparatus reagents, procedures and some applications. Agricultural Handbook, 379. Washington, DC.: 1970.

KEPLIN, L.A.S. Silagem de milho de alta qualidade. In: CARLESSO, R.; ROSA, G.M.; PETRY, M.T. et al. Irrigação por aspersão no Rio Grande do Sul. Santa Maria: Universidade Federal de Santa Maria, 2001. p.36-58.

LATIN AMERICAN TABLES OF FEED COMPOSITION. Flórida: University of Florida, 1974. p.11-16.

McDOnALD, P.; HENDERSON, N.; HERON, S. The biochemistry of silage. 2.ed. New York: Chalcombe Publications, 1991. 339p.

MORENO, J.A. Clima do Rio Grande do Sul. Porto Alegre: Secretaria da Agricultura. 1961. 41p.

MÜLBACH, P.R.F. Silagem: produção com controle de perdas. In: LOBATO, J.F.P., BARCELLOS, J.O.J.; KESSLER, A.M.. et al. (Eds.) Produção de bovinos de corte. Porto Alegre: EDIPUCRS, 1999. p.97-120.

NATIONAL RESEARCH COUNCIL - NRC. Nutrient requeriments of domestic animals. 6.rev.ed. Washington D.C.: National Academy Press. 1984. p.90.

NUSSIO, L.G. Cultura de milho para produção de silagem de alto valor alimentício. In: PEIXOTO, A.M. et al. In: SIMPÓSIO SOBRE NUTRIÇÃO DE BOVINOS, 4., 1991, Piracicaba. Anais... Piracicaba: Fundação de Estudos Agrários "Luiz de Queiroz", 1991.p.59-168.
NUSSIO, L.G. Silagem de milho. In: PEIXOTO, A.M. et al. Alimentação suplementar. Piracicaba: Fundação de Estudos Agrários "Luiz de Queiroz", 1999. p.27-46.

PIMENTEL, J.J.O.; SILVA, J.F.C.; VALADARES FILHO, S.C. et al. Efeito da suplementação protéica no valor nutritivo de silagens de milho e sorgo. Revista da Sociedade Brasileira de Zootecnia, v.27, n.5 p.1042-1049, 1998.

ROSA, J.R.P.; RESTLE, J.; SILVA, J.H.S. et al. Avaliação da silagem de diferentes híbridos de milho (Zea mays, L.) por meio do desempenho de bezerros confinados em fase de crescimento. Revista Brasileira de Zootecnia, v.33, 2004. (no prelo)

STATISTICAL ANALYSES SYSTEM - SAS. SAS/STAT user's guide: statistics 7.ed. Version 6.11 v.2. Cary: 1997. 943 p.

SILVA, J.M.; FEIJÓ, G.L.D.; THIAGO, L.R.L.S. et al. Desempenho animal e avaliação do potencial produtivo de forragens para ensilagem por intermédio de diferentes fontes de suplementação nitrogenada. Revista da Sociedade Brasileira de Zootecnia, v.28, n.3, p.642-653, 1999a.

SILVA, F.F.; GONÇALVES, L.C.; RODRIGUEZ, J.A.S. et al. Qualidade de silagens de híbridos de sorgo (Sorghum bicolor (L.) Moench) de portes baixo, médio e alto com diferentes proporções de colmo+folhas/panícula. 1. Avaliação do processo fermentativo. Revista da Sociedade Brasileira de Zootecnia, v.28, n.1, p.14-20, 1999b.

TILLEY, J.M.; TERRY R.A. A two-stage technique for the in vitro digestion of forage crops. Journal of British Grassland Society, v.18, p.104-111, 1963.

Van SOEST, P.J. Nutritional ecology of the ruminant. 2.ed. Ithaca New York: Cornell University Press, 1994. 476p.

Recebido em: 22/08/02 Aceito em: 04/08/03 